\title{
Correspondence
}

The assessment and management of
risk in psychiatry: can we do better? risk in psychiatry: can we do better?

Sir: "Evaluative studies have uniformly demonstrated that anxieties surrounding the relocation of long-stay patients were unfounded" (Psychiatric Bulletin, May 1997, 21, 283-285). Dr Frank Holloway's astonishing Panglossian statement does little to inspire confidence in his case for selective calculated risk taking. In support he cites only the earliest Team for the Assessment of Psychiatric Services (TAPS) report, ignoring its more cautious successors and a great mass of reports revealing major and widespread failures in community support for the seriously mentally ill.

Those of us involved in rehabilitation psychiatry in the 1950s have troubled memories of the deadly toll, undocumented and indeed scarcely heeded by organised psychiatry, that followed the euphoria of drugs at last effective in treating schizophrenia and massive discharges from hospital. It seems the lessons are still unlearned.

We would all like to see comprehensive services providing effective treatment and support for all who need them, but such blinkered historical revisionism can only hinder the achievement of this goal.

A MORRISON, Consultant Psychiatrist (retired), Fife Psychiatric Service

Author's reply: Dr Morrison accuses me of a Panglossian statement. No one who works as a clinician and manager in an inner-London psychiatric service could conceivably hold the view expressed by Professor Pangloss that we live in the best of all possible worlds. The pressures under which our services currently work have recently been well documented (Johnson et al. 1997). There is undoubtedly a stark gap between what could be done for our patients and their carers and what is delivered; a gap which could partially be bridged by more adequate funding.

The TAPS study is by far the most comprehensive evaluation of mental hospital closure that has been carried out. Summarising the outcome for non-demented long-stay patients Leff (1997) concludes that "the benefits of the move from hospital to community care for this sample of long-stay patients clearly outweigh the disadvantages". Similarly Treiman \& Wills (1997) report "we find plenty of evidence that the reprovision for elderly psychiatric patients . . . was highly successful". This hardly reflects recantation of early optimism. It is clear that mental hospital closure can be carried out responsibly and successfully, a finding corroborated by other less extensive UK studies of closure programmes.

However, hospital closure is not, as initially suggested, a cheap option: "community care costs are marginally but significantly greater than hospital costs" (Beecham et al, 1997). More disturbing is the finding of the TAPS study of acute in-patient services which identified a "failure to address the needs of the new generation of long-term mentally ill people means that many patients with active symptoms, who would have previously remained in hospital are being denied admission or are discharged to a badly organised and underfunded system of "community care'" (Sammut \& Leff, 1997).

The illustrative point that I was making in my article, that the supposedly risky undertaking of moving long-stay patients out of a mental hospital in a responsible fashion could be to their benefit, is strongly supported by empirical evidence. There are, however, no grounds for complacency about the overall quality of provision for the mentally ill in the UK.

Beecham. J.. Hallam. A.. KNapP. M., et al (1997) Costing care in hospital and in the community. In Care in the Community. Ilusion or Reality? (ed. J. Leff). Chichester: Wiley.

Johnson, S., ThORNICROFT, G. ChiSholm, D., et al (1997) London's Mental Health Services. London: King's Fund.

LEFF, J. (1997) The outcome for the long-stay nondemented patients. In Care in the Community. Illusion or Reality? (ed. J. Leff). Chichester: Wiley.

SAMMUT, R. \& LEFF, J. (1997) The reprovision of acute services. In Care in the Community. Ilusion or Reality? (ed. J. Leff). Chichester: Wiley.

TREIMAN \& WILLS, W. (1997) The psychogeriatric population: in transition from hospital to community-based services. In Care in the Community. Ilusion or Reality? (ed. J. Leff). Chichester: Wiley.

Frank Holloway, Consultant Psychiatrist and Clinical Director, Community Directorate, Maudsley Hospital, London SE5 8AZ

\section{Inquiries: who needs them?}

Sir: Muijen's editorial (Psychiatric Bulletin. March $1997,21,132-133)$ calls for a change in the way independent homicide inquiries are currently managed. Many of the points he relies on have been aired before: they are too costly, there have been too many of them, they all say the same thing 